\title{
Influencia liberal estadounidense en el Ejército colombiano, 1880-1904*
}

DOI: http://dx.doi.org/10.21830/19006586.182

Recibido: 20 de marzo de 2016 Aceptado: 5 de junio de 2017

The US Liberal Influence in the Colombian Army (1880-1904)

L'influence libérale des États-Unis dans l'arrmée colombienne (1880-1904)

Influência liberal norte-americana no Exército Colombiano (1880-1904)

Ricardo Esquivel Triana a

* Artículo de reflexión del proyecto sobre la formación militar en Colombia; producto para los grupos de memoria histórica de la Dirección de Apoyo a la Transición y Memoria, DATRA - CEDE 11.

${ }^{a}$ Departamento Jurídico Integral - CEDE 11, Ejército Nacional - Bogotá, Colombia. Ph. D. en Historia, Universidad Nacional de Colombia. Asesor Historia y Memoria - Ejército Nacional. <resquivelt@unal.edu.co>. 
Resumen. Este artículo caracteriza la influencia liberal estadounidense sobre el Ejército colombiano entre 1880 y 1904 . En cuanto al aspecto teórico, asume que la formación del ejército es consustancial al Estadonación, reflejado en sus entornos conflictivos, pero no analiza el pensamiento liberal ni sus manifestaciones partidistas. Tal influencia se basó en la táctica del militar liberal Emory Upton, la cual superó las doctrinas europeas que regían en Colombia. Una misión estadounidense, veterana en las "guerras indias", la impuso desde la Escuela Militar, especialmente Henry Lemly, oficial que también fue agente en la compra de armamento, impulsor de deportes y escritor costumbrista.

Palabras clave: educación militar; estrategia militar; historia militar - Colombia, 1880-1904.

Abstract. This article characterizes the liberal U. S. influence on the Colombian Army, 1880-1904. In theory, it assumes that the formation of the army is inherent to nation-state, reflected in its conflictive environments; but not analyze liberal thought or its partisan manifestations. Such influence was based on Emory Upton tactics, a liberal military, surpassing the European doctrines that prevailed in Colombia. From the military school, it imposed by U. S. mission, veteran in the "Indian wars"; especially by Henry Lemly, an officer who was also an agent in the purchase of weapons, a sports promoter and writer of types and customs.

Keywords: military education; military history - Colombia, 1880-1904; military strategy.

Résumé. Cet article caractérise l'influence libérale des États-Unis sur l'armée colombienne entre 1880 et 1904. Dans le théorique il assume que la formation de l'armée est inhérente à l'État-nation, reflétée dans ses environnements de conflit; mais il n'analyser la pensée libérale, ni ses manifestations partisanes. Cette influence était basée sur la tactique d'Emory Upton, un militaire libéral, en surpassant les doctrines européennes qui étaient en vigueur en Colombie. Depuis l'École Militaire elle est imposé par une mission américaine, vétéran dans les "guerres indiennes "; spécialement par Henry Lemly, un militaire qui était aussi agent dans l'achat d'armement, un promoteur de sport et un écrivain de types coutumes.

Mots-clés: éducation militaire; Histoire militaire-Colombie, 1880-1904; stratégie militaire.

Resumo. Este artigo caracteriza a influência liberal americana sobre o Exército Colombiano entre 1880 e 1904. Em teoria pressupõe que a formação do exército é inseparável do Estado-nação, refletido em seus ambientes conflitantes; mas não analisa o pensamento liberal, nem suas manifestações partidárias. Essa influência foi baseada nas táticas de Emory Upton, um militar liberal, superando as doutrinas europeias que prevaleceram na Colômbia. Desde a escola militar foi imposta uma missão americana, composta por veteranos nas "guerras indígenas"; especialmente Henry Lemly, que também era agente oficial na compra de armas, incentivador de esportes e escritor costumes.

Palavras chave: educação militar; estratégia militar; história militar - Colômbia, 1880-1904.

\section{Introducción}

En la historiografía sobre el conflicto armado interno en Colombia, un lugar común es considerar que este se debió en parte a los acaecidos en el siglo XIX (Comisión Histórica del Conflicto y sus Víctimas, 2015, pp. I-9, II-34). No obstante, si entonces el país sufrió varios conflictos, estos no alteraron los fundamentos de la institucionalidad colombiana, como la democracia representativa, las libertades públicas y el mismo civilismo de los dirigentes (Palacios, 1999, p. 251; Valencia, 1987, 
p. 43). Al preguntar cómo en medio del conflicto se logró preservar tal institucionalidad, podría afirmarse que ello fue gracias a la existencia de un Ejército Nacional; de hecho, la teoría política acepta que una de las tareas del Estado es neutralizar también las amenazas dentro del propio territorio (Deas, 1994, p. 10; Mann, 1991, p. 56).

La misma historiografía, como la preeminencia dada a la memoria del conflicto, ha tendido a soslayar el papel del Ejército colombiano en la formación del Estado-nación ${ }^{1}$ y su aporte a la paz. Mientras aquella insiste en que durante el siglo XIX en la formación del Estado-nación colombiano subyacen tendencias liberales, así como estas en parte tuvieron influencia de Estados Unidos, se omite que ambas, las tendencias liberales y su ascendiente estadounidense, incidieron directamente sobre la formación del Ejército colombiano. Por lo anterior, el propósito de este artículo es responder ¿`cómo se caracterizó la influencia liberal estadounidense sobre aquel ejército?

En Colombia, desde 1880 y durante el siguiente cuarto de siglo, los militares profesionales adoptaron progresivamente las Tácticas de infantería del estadounidense Emory Upton. En relación con la formación del Estado-nación, algo no circunstancial y que alejaba al Ejército del militarismo. Dicha obra, más que simplemente ofrecer unas tácticas de combate, vino a consolidar el pensamiento liberal en el Ejército colombiano. Entonces Colombia, aparte de regirse por la Constitución de 1863, promovía un precepto liberal al procurar la educación en todas las instancias (Cardona, 2013, párr. 1).

Este proceso educativo, podría considerarse, se inició y fue liderado por la educación profesional de los militares (Ortiz, 2014, p. 88). El Colegio Militar abrió en 1847 gracias al general Tomás Cipriano de Mosquera, un controvertido liberal. El director de este Colegio, el coronel Agustín Codazzi, lideró con sus alumnos la Comisión Corográfica, que levantó la nueva cartografía de la República. En 1867 el Colegio fue adscrito a la Universidad Nacional como Escuela de Ingeniería, civil y militar, con lo cual fortaleció su estirpe liberal. La adopción de las tácticas militares, desde 1880, consolidaría la reforma del Ejército para ajustarse a los entornos internos y externos de final del siglo XIX.

Por lo mismo, la adopción de tácticas evidencia una política militar — esta que define el enfoque del presente artículo-; como tal, aquella política pública estaba dirigida a la administración y gestión de los recursos disponibles (Puell, 2000, pp. 16-19). Más claro, la adopción de tácticas es muy importante considerando que un ejército no puede cambiar de un día para otro, pues el cambio es más el resultado de un largo proceso. Algunos denominan a ese proceso una reforma militar, la cual supone no solo convertir al ejército "en una fuerza de combate eficiente", sino que además debe "armonizar la función militar con las instituciones democráticas" vigentes (Agüero, 1995, p. 206).

El periodo de análisis enfatiza desde el año 1880, cuando llegó a Colombia la primera misión estadounidense para enseńanza en la Escuela Militar, hasta 1904, cuando se abandonó su enfoque táctico para las tropas. Este aspecto refuerza la importancia del tema tratado, pues

1 La "formación del Estado-nación", como proceso histórico, comprende la formación del sentido de comunidad política y de un aparato de Estado. Proceso diferente en cada Estado-nación, pudiendo predominar el conflicto por periodos largos para definir instancias de poder, modelos de Estado e intercambios económicos. Tal concepto no es sinónimo de 'construcción de Estado', aun diferenciando 'state-building' y 'nation-building' (Dinnen, 2007, p. 2), más usado respecto a intervención en los 'Estados fallidos” (Bogdandy, Häußler, Hanschmann \& Utz, 2005, p. 580). 
Colombia puede ser uno de los primeros países de la región que adoptó una misión y una táctica estadounidense. Esta influencia y la llegada posterior de asesores chilenos, como la fugaz misión francesa de 1898, refutarían otro lugar común en la historiografía, el cual insiste en que "como ejércitos modernos, las fuerzas armadas latinoamericanas han estado influidas por ejércitos extra continentales" (Varas, 1988, p. 17); concepción inaplicable para el caso colombiano.

La adopción de tales tácticas habría coadyuvado a alejar al Ejército colombiano del militarismo, dada su tendencia a humanizar la guerra. En efecto, el modelo de Upton, entre otras virtudes, se orientó a disminuir las bajas en el combate. Con la adopción de dichas tácticas por el Ejército colombiano, los conflictos armados del siglo XIX, aunque intermitentes, resultarían menos onerosos para las fuerzas enfrentadas y para la misma población, aspecto que será objeto de análisis en un trabajo futuro. Por ende, aquí tampoco se analizará el ámbito militar de los conflictos colombianos, ni las expresiones partidistas o de gobierno de las vertientes liberales en Colombia.

Para el propósito de este artículo, se revisaron cinco aspectos: i) los entornos conflictivos para una reforma militar, ii) el perfil liberal de Upton, iii) la adopción de tácticas en el contexto colombiano, iv) el pragmatismo estadounidense en la escuela colombiana y, finalmente, $v$ ) el perfil liberal costumbrista de Henry Lemly.

\section{Entornos conflictivos para una reforma militar}

La formación de un ejército nacional es consustancial con la del Estado-nación, un reflejo de los conflictos subyacentes. Esto lo confirman Colombia y los EE. UU., que, sin ser iguales, formaron sus ejércitos en entornos comparables, como se verá en este apartado. Para los EE. UU., país de conflictos intermitentes ${ }^{2}$, estos fueron de tres tipos.

El primer tipo de conflicto, desde su independencia, consistió en no menos de 26 "guerras indias", mezcladas con la expansión de sus fronteras continentales y con las acciones orientadas a asegurar los mercados internos hacia el oeste. La política para desplazar los indios a reservas fue reiniciada en 1812 por A. Jackson, pero entre 1860 y 1890 tuvo lugar una nueva fase de guerras ${ }^{3}$. En este periodo ocurrieron los combates de 1876 en Rosebud y Little Big Horn, donde el Ejército estadounidense sufrió su peor derrota, y de 1890, cuando el mismo Ejercitó masacró mujeres y niños indios en Wounded Knee.

El segundo tipo fueron las rebeliones civiles, entre las cuales se destaca la Guerra de Secesión (1861-1865). Cuando se inició este enfrentamiento, el Ejército regular alcanzaba 16.000 efectivos, dispersos contra los indios, mientras que las milicias estatales eran de pobrísimo nivel. Si bien ambos bandos crearon cuerpos de voluntarios, recibieron apoyo foráneo, como la industria

2 "For even though the country during the Indian campaigns could not be said to be at peace [...]" (Stewart, 2001, p. 301). Desde su independencia y hasta hoy, los EE. UU. han vivido en paz solo 21 años, es decir que el 93\% de su existencia han estado en algún conflicto externo o interno. No hubo una década, ni un presidente, sin guerra (Washington Blog, 2015).

3 Entre otras figuran con nombre específico "guerra [...]": Shawnee (Tecumseh) 1811 y 1814; Creek 1813; Seminolas 1817, 1835-42 y 1855-58; indios de Texas 1820-1875; Arikara 1823; Ute 1850-1923; Apache 1851-1900; Puguet Sound y Rogue River 1855; Yakima 1855-58; Navajo 1858-66; Paiute 1860; Yavapai 1861-75; Dakota 1862; Cheyenne y Sioux 1863-65 y 1874; Snake 1864-68; Comanche 1867-75; 'Gran guerra Sioux' 1876 y 1890; Bannock 1878; Cheyenne 1878; Shoshone 1879; Apache 187981; Yaqui 1896-1918 (History.com, 2010). 
y los ferrocarriles, sectores que demostraron su capacidad decisoria; por su parte, los europeos la juzgaron una guerra entre aficionados. Cuando finalizó esta conflagración, los voluntarios y las milicias se redujeron, y el Ejército fue redesplegado, por ejemplo, enviando más tropas a Texas para someter los reductos sureños, a los indios y reforzar la frontera con México, invadido entonces por Francia. En 1871, el Ejército alcanzaba 28.000 efectivos y en 1878 la marina contaba con 48 buques, la mayoría de vela (Mújica, 2014, pp. 166 y 174).

Finalmente, el tercer tipo de conflictos de los EE. UU. se caracterizan por su proyección internacional. Suman hasta doce para conquistar territorio, por ejemplo contra México (1846) y contra Espańa (1898), o para imponer su comercio en el Pacífico oriental; sin incluir sus "tareas de policía” en Centroamérica y el Caribe. Durante el siglo XIX, los EE. UU. mantuvieron una política aislacionista porque no percibían desafíos externos a su seguridad y confiaban en la doctrina de defensa costera de Dennis Mahan. Así "el Ejército no se ocupaba sino del teatro de la lucha, consideraba la batalla como un fin en sí, y no establecía ningún lazo entre la guerra y los objetivos políticos del país" (Duroselle, 1965, pp. 20, 22).

El triunfo alemán de 1870 sobre Francia interesó poco a los estadounidenses, y aunque Emory Upton fue enviado a estudiarlo, sus recomendaciones solo calaron al entrar el siglo XX. De hecho, en la guerra contra España, el Ejército regular de los EE. UU. volvió a reforzarse con cuerpos de voluntarios. Al mando de uno de estos, el político Theodore Roosevelt constató que tal Ejército estuvo a "distancia mensurable de un desastre militar" (Arancibia, 2002, p. 52). Pero esta guerra seguía una nueva doctrina expuesta en 1890 por Alfred Mahan: los EE. UU. debían proyectar poder naval dado su condominio del Caribe con Gran Bretańa - por el tratado ClaytonBulwer (1850) — y en respuesta a la construcción de un canal en Panamá por los franceses (Mahan, 2000, p. 187).

Como consecuencia de esa guerra, una década después permanecían 16.000 efectivos en Filipinas y otros 4.000 en Cuba, sumando cerca de 3.400 del servicio de sanidad, lo cual significaba que el Ejército había duplicado sus efectivos. El secretario de Guerra Elihu Root (18991904) intentó modernizar ese Ejército, pese a la oposición del Congreso, creando en 1901 el War College para el estado mayor general y basándose en la obra de Upton, la cual había sido refrendada entonces por los libros del coronel T. Schwann y del británico S. Wilkinson. Pero sería el general Leonard Wood, un médico de Harvard, quien como jefe de estado mayor promovió desde 1910 una conciencia de la defensa nacional y de preparar la movilización del Ejército en tiempo de paz (Clark, 2009).

En contraste con los EE. UU., después de su independencia Colombia no impulsó conflictos para desplazar indígenas ni conquistar territorios. Asimismo, en el siglo XIX Colombia tuvo una articulación débil con la economía mundial (Ocampo, 1984, p. 25). Si por el contrario Colombia sufrió más de 18 agresiones externas ${ }^{5}$, estas le asemejan a los EE. UU. en su interacción

4 Dennis H. Mahan (1802-1871), egresado y profesor de ingeniería de West Point, impulsor del profesionalismo militar. Sus enseñanzas sobre fortificación y estrategia eran seguidas por oficiales de ambos bandos en la Guerra de Secesión, influencia que perduró hasta la Primera Guerra Mundial; progenitor de Alfred Mahan.

5 Entre las agresiones contra Colombia están: invasión por tropas peruanas 1829 y 1911; ecuatorianas 1832, 1839, 1863 y 1900; venezolanas 1845, 1847, 1855 y 1900; nicaragüenses 1901. Toma británica de la Costa de Mosquitia desde 1847. Bloqueo marítimo y/o bombardeo desde flotas francesas 1833 y 1861; británicas 1836 y 1856; italianas 1885 y 1898; alemana 1870. Además las catorce intervenciones estadounidenses entre 1855 a 1903 en Panamá, no todas solicitadas (Esquivel, 2010, p. 79). 
con el segundo tipo de conflictos. En particular, Colombia sufrió intermitentes rebeliones civiles, hasta ocho nacionales ${ }^{6}$, la más traumática de las cuales tuvo lugar en 1899 , pero solo en la de 1860 vencieron los rebeldes y se generó una reforma del Ejército.

Cuando se inició el conflicto de 1860, el Ejército permanente de Colombia escasamente alcanzaba los 1.500 efectivos, dispersos en las principales capitales del país, mientras que las milicias estatales solo existían de nombre. Adviértase que poco antes el entonces secretario de Guerra, Rafael Núñez, redujo el Ejército a 373 efectivos, al suprimir la guarnición de Panamá y reducir la de Bolívar (Martínez, 2012, p. 25).

Aquel conflicto no fue generalizado ni continuo. Primero los conservadores se alzaron contra el gobierno liberal de Santander, luego los liberales derrocaron al gobierno conservador de Bolívar, y así sucesivamente. Entre pactos de paz y nuevos combates, en julio de 1861 Mosquera se tomó a Bogotá.

En seguida se firmó el Pacto de Unión, que, con la renuencia de Antioquia y Panamá, convocó la constituyente de Rionegro y reorganizó el Ejército bajo el nombre de Guardia Colombiana. Sin que cesaran las escaramuzas con los reductos rebeldes, tal reorganización aglutinó militares del viejo Ejército y voluntarios reclutados durante el conflicto. Cuando terminó la conflagración, el Ejército, antes que reducirse, debió redesplegarse en el sur del país entre 1862 y 1863 para expulsar una invasión ecuatoriana. En 1864, ese nuevo Ejército permanente sumaba aproximadamente 3.415 efectivos, pero durante la década siguiente fueron en promedio 1.500, distribuidos en tres batallones de infantería ligera, uno de artillería y uno de zapadores (Martínez, 2012, pp. 100 y 115).

Excepto el mencionado conflicto con Ecuador, incluidos los cuatro conflictos internos de 1876 a 1899, el Ejército permanente colombiano se mantuvo en guarnición en las principales capitales del país. Hasta 1900, inclusive cuando se enviaron tropas a Riohacha y Cúcuta para expulsar invasores venezolanos, o en 1911 para expulsar los peruanos de La Pedrera (Amazonas), el Ejército colombiano nunca fue desplegado para cumplir misiones de conquista o dominio territorial como hicieran sus homólogos en otras partes del continente. Los dirigentes colombianos nunca han considerado la guerra externa como un medio para los objetivos políticos del país, confiados en el derecho internacional y el arbitraje (Ministerio de Relaciones Exteriores, 1957, p. X).

La construcción de un canal por Panamá, adelantada por los franceses entre 1878 y 1888, puede que también incitara algún cambio. Núñez, quien dijimos redujo a su mínima expresión el Ejército, planteó en 1875 modernizarlo y lo reiteró en 1885 en función de no poner en peligro la soberanía en Panamá (Diario Oficial, 1885, noviembre 12, p. 15.109). El proceso de modernización fue un proyecto liberal desde la apertura del Colegio Militar en 1847, la instauración de la Guardia Colombiana en 1861 y la llegada de una misión militar estadounidense en 1880. Paradójicamente, fue obra de Miguel A. Caro, un nacionalista opositor del liberalismo ${ }^{7}$, unificar los fundamentos del Ejército Nacional en la Constitución de 1886 y consolidar la legislación que lo estructuró desde 1896.

6 Se sugiere que los conflictos de 1839, 1851 y 1854 dirimieron el sujeto político; en 1860, 1876 y 1885 el régimen político; en 1895 y 1899 los alcances del régimen centralista (González, 2006, p. 23-24).

7 En el siglo XIX, en Colombia, un partido nacionalista fue plataforma política de Mosquera para su frustrada candidatura en 1856. También constituyeron uno Núńez, liberal, y Caro, militante católico; este Partido Nacional fue artífice de la Constitución de 1886, así como gobernó entre 1886 y 1900 incluyendo cuatro presidentes: Núnez, Holguín, Caro y Sanclemente. Como tal los nacionalistas, y Caro en particular, se opusieron fuertemente al Partido Conservador, considerando que estaba contaminado de ideas liberales (Pérez, 2007, p. 222). 


\section{El pensador liberal Emory Upton}

Emory Upton (1839-1881) no solo fue un militar de carrera, sino que además como liberal fue artífice de la reforma del Ejército de los EE. UU. Hijo de granjeros, terminó su educación básica en un colegio que era foco del antiesclavismo en el país, de modo que compartió clases con negros y mujeres. Becado para la Academia Militar de West Point, se graduó como subteniente en mayo de 1861, al mes de estallar la Guerra de Secesión en ese país. De inmediato pasó a un batallón de artillería del ejército unionista, y aunque fue herido en combate, siguió cumpliendo sus tareas. Durante sus primeras campañas, el éxito lo llevó de comandar una batería de artillería a una brigada de artillería.

Upton fue un militar ejemplo del pensamiento liberal. Como cadete en West Point, en alguna ocasión se batió a duelo contra un compañero para hacer valer su credo antiesclavista (Kirshner, 1999, p. 7). Por lo mismo, permaneció como oficial en el ejército unionista contra los rebeldes sureños, caracterizándose por exigir severa disciplina a sus subalternos, pero siempre desde el frente de combate. En 1862, nombrado coronel de un regimiento de infantería de voluntarios, asumió una actitud crítica para desarrollar alternativas menos sangrientas, luego de que sufriera el $60 \%$ de bajas en un ataque frontal. $\mathrm{Al}$ ańo siguiente, Upton condujo un ataque exitoso empleando una nueva táctica, que consistía en formar las tropas no en líneas sino en columna.

Probó sus tácticas exitosas en la Batalla de Opequan, donde resultó herido y debió reemplazar a su jefe de división, quien había muerto. De allí fue nombrado general de voluntarios, con apenas 25 años de edad. El último año de la guerra, en 1865, pasó a ser jefe de una división de caballería (Cullum, 1868, p. 526), con la cual experimentó la táctica de desmontar en batalla, aprovechando el nuevo fusil Spencer de retrocarga, todo un preludio de la infantería móvil (Baker, 2012, párr. 9). En Columbus su división probó un ataque nocturno, con el cual lograron destruir un objetivo sureńo y capturar 1.600 prisioneros. Terminada la guerra, Upton siguió como comandante en unidades de caballería hasta que fue ascendido en 1866 a teniente coronel del ejército regular ${ }^{8}$ y asignado a West Point para evaluar las tácticas de infantería usadas.

Habiendo acumulado experiencia al frente de unidades de artillería, infantería y caballería, e innovado tácticas para ellas, Upton no solo era un oficial excepcional, sino que desde West Point pudo difundir tal bagaje. Justo en 1867 el Ejército de los EE. UU. adoptó sus Tácticas de infantería adaptándolas al nuevo fusil de retrocarga, considerado el principal progreso después de casi un siglo de seguir el modelo francés (Kirshner, 1999, p. 144). Upton promovía allí el orden abierto, presentar un frente de cuatro soldados y formar los regimientos de a tres batallones. Lo mejor, otorgaba más responsabilidad individual; era una táctica "hecha a la medida de un pueblo libre" (Baker, 2012, párr. 1).

Si bien Upton se propuso cambiar primero las tácticas del Ejército, luego procuró cambiar al Ejército en sí (Fitzpatrick, 2001, p. 355). A finales de 1867 fue enviado como observador a

8 Upton fue distinguido con el Brevet de General, una mención de grado por méritos sin derechos para ascenso en el ejército regular o servía para comandar unidades de voluntarios. Algo distinto en la Colombia decimonónica, la distinción entre empleo y destino. El empleo era el grado efectivo al que ascendía un oficial del ejército regular según las leyes; el destino era el mando en una unidad, aunque por imprevistos no siempre se cumplía la equivalencia, por ejemplo, un coronel debía mandar un regimiento, no un mayor. Casos en los que tampoco ganaba derechos para ascenso ni aumento salarial (Confederación Granadina, 1859, p. 318). 
Europa. Luego de un breve comando de infantería, de nuevo, de 1870 a 1875 permaneció en West Point. Aquí se desempeñó como comandante de cadetes e instructor en tácticas de artillería, infantería y caballería. En 1875 cumplió otro viaje anual por Asia y Europa, donde confirmó las ventajas del sistema alemán de movilización y de estado mayor, que recomendó fuera adaptado (Ambrose, 1964, p. 27) en lugar del modelo francés, practicado desde la independencia en los EE. UU. Del viaje por diez países y de la recomendación se publicó en 1878 su libro Armies of Asia and Europe.

En la Escuela de Práctica de Artillería, de 1877 a 1880, impulsó las tácticas de armas combinadas. Siendo la única escuela de posgrado militar en los EE. UU., la convirtió en un modelo para crear las de otras armas (Shrader, 2000, párr. 2). Pero allí dedicó más energía al análisis de la historia militar de la Guerra de Secesión para sustentar la necesidad de una reforma estructural, foco de su libro póstumo The Military Policy of the United States.

En esa obra demostró que $i$ ) la libertad se exponía a más peligros por la falta de un ejército permanente; ii) que la independencia se arriesgaba más por la inexperiencia de los políticos para manejar asuntos militares, y iii) que la seguridad de un gobierno dependía de las tropas regulares (Kirshner, 1999, p. 146). Finalmente concluye que, al no prepararse para la guerra, o sea, por carecer de una política militar, los EE. UU. habían sacrificado más vidas y presupuestos para enfrentar las que se presentaron (Millis, 1956, p. 125).

Los avances del libro los discutió con W. Conant, el editor del Army and Navy Journal, y con un reducido entorno de allegados. También lo hizo con James Garfield, otro antiesclavista, líder militar durante la Guerra de Secesión y fugazmente presidente de los EE. UU. en 1881 antes de que fuera asesinado. Pero el mayor apoyo lo recibió del general William Sherman, entonces comandante general del Ejército, quien le facilitó difundir su obra. En ella, Upton no solo promovía el modelo alemán de estado mayor y de movilización, sino que además insistía en que el comando del Ejército tuviera una sección para estudiar la historia de las guerras estadounidenses.

Para Upton, los EE. UU. debían abandonar su sistema dual de milicias de voluntarios y ejército regular, de tal forma que este último ejército tuviera el monopolio de la fuerza, como él mismo había constatado en los países europeos. De acuerdo con su pensamiento, una cosa era la confederación, donde las tropas eran de los estados, con oficiales controlados por sus políticos y equipadas por los mismos ciudadanos; un sistema que demostró ser inefectivo en las guerras de 1812 contra México e incluso en la Guerra de Secesión. Otra cosa era el gobierno federal, el que debería encargarse de equipar, entrenar y dotar con oficiales profesionales a las unidades de voluntarios, con lo cual se garantizaría una verdadera defensa nacional y el control de desafíos internos (Fitzpatrick, 2001, p. 382 y 387).

Upton insistió en que el Ejército debía prepararse para las amenazas externas, nunca justificar su existencia sobre la seguridad interna (Ambrose, 1964, p. 31). Sobra acotar que estas ideas de reforma tuvieron poco eco en el Congreso y se criticó a Upton por pretender acabar la tradición estadounidense del ciudadano armado. Aunque había quedado incompleto, el manuscrito del libro llegó en 1899 a manos de Elihu Root, nuevo secretario de Guerra, a quien le convenía en ese momento un ejército regular para defender las posesiones recién arrebatadas por los EE. UU. a Espańa. En 1904, Root hizo publicar póstumamente el libro ${ }^{9}$ y se convirtió en la guía para

9 Root, abogado corporativo, fue nombrado secretario de Guerra (1899-1904) por el presidente McKinley. Se atribuye a Root la transformación del Departamento de Guerra, abrir escuelas de las armas y fortalecer el control sobre la Guardia Nacional. 
profesionalizar el Ejército de los EE. UU., además de que luego se puso a prueba en la Primera Guerra Mundial.

Pero el debate sobre cómo la reforma propuesta por Upton vulneraba la tradición estadounidense del ciudadano armado se reactivó después de la Primera Guerra Mundial. El mismo Ambrose (1964, p. 31), citado más arriba y biógrafo de Upton ${ }^{10}$, lo criticó por querer imponer un gran ejército permanente. El número de críticos aumentó sin que entendieran que la esencia de la política militar no era la cantidad de soldados, sino preparar un ejército para cuando surgiera la necesidad de usarlo (Fitzpatrick, 2001, p. 359).

\section{De las tácticas europeas a las estadounidenses}

Si bien el Colegio Militar inaugurado por Mosquera se inspiró en West Point, las tácticas estadounidenses solo se impusieron cuando arribó en 1880 una misión de ese país. Al respecto se afirma que Simón Bolívar imitaba a Napoleón y que el ejército libertador adoptó los manuales franceses e ingleses, mientras que Francisco de Paula Santander seguía la vieja táctica espańola (Thibaud, 2003, pp. 322, 393 y 418). Lo cierto es que desde 1821 el Ejército colombiano dispuso de formas clásicas de organización a la francesa que coexistían con las formas de operación de guerrillas a la española; la interacción entre manuales de ambas vertientes se evidenció en el conflicto de 1876 (Ortiz, 2004, p. 60).

Específicamente, el Código Militar de Cundinamarca, de 1858, fijaba por armas los manuales respectivos así: en primer lugar, Táctica para las maniobras de artillería del ejército de la Nueva Granada, de 1848; luego, Reglamento para el ejercicio y maniobras de infantería, de 1808, y el Tratado de guerrilla para el uso de las tropas ligeras de la República de Colombia, de 1821, estos dos de origen espańol; por último, Reglamento para el ejercicio y maniobras de la caballería, español de 1815 (Confederación Granadina, 1859, p. 387). Ciertamente, la infantería y la caballería seguían rigiéndose por las tácticas espańolas con algunos ajustes, mientras que la artillería puede que se actualizara por alguna gestión del primer gobierno de Mosquera.

Incluso en 1878, en Bogotá se publicó el manual del belga Sagher sobre tácticas de infantería, caballería y artillería, en traducción hecha por el capitán Candelario Obeso. Este libro fue acogido por una comisión del Ejército colombiano encabezada por el general Rudecindo López, quien junto a otros veintiséis oficiales firmaron el prólogo (Sagher, 1878, p. 4). La actualidad del libro era innegable en cuanto enfatizaba las experiencias militares europeas de las guerras desde Crimea hasta el triunfo alemán de 1870.

\footnotetext{
También se ocupó de administrar las nuevas adquisiciones: Cuba, Puerto Rico y Filipinas. El presidente T. Roosevelt lo nombró secretario de Estado (1905-1909). Desde aquí promovió relaciones con el Lejano Oriente, acercarse a Suramérica y afianzar el arbitraje internacional en Centroamérica. Luego, como senador, se opuso a la política de neutralidad del presidente W. Wilson; en 1921 fue delegado a la Conferencia de limitación de armas navales y en la instauración de la Corte de Justicia Internacional (Nobel Foundation, 2014).

10 Fitzpatrick (2001) objeta explícitamente el análisis de Ambrose sobre Upton. El foco de la objeción se ciñe al reiterativo debate en los EE. UU.: mantener un gran ejército permanente o confiar en las milicias de ciudadanos.
} 
La transformación táctica era crucial para este periodo. Al estallar el conflicto de 1876, el gobierno liberal adquirió 5.500 fusiles Remington de retrocarga, mientras que los rebeldes obtuvieron otros 3.000, lo cual pudo incrementar la mortandad en los combates. Pero la contundencia de la disciplina de fuego tendía a disolverse por dos factores: i) el número de efectivos: el ejército gubernamental aumentó hasta 30.000 y los rebeldes sumaban otros 10.000 efectivos; ii), por ende, aquellos fueron armados con una miscelánea de fusiles: Winchester, Dreyse, Lefaucheux, Chaszepol, Peabody, Spencer, Máuser, Martini, Minié, Herdán, incluso algunos de pedernal, arcabuces y mosquetes (Ortiz, 2004, p. 101).

Por eso, cuando en 1880 se reabrió la Escuela Militar, uno de los primeros objetivos de la misión estadounidense, conformada por los oficiales Thomas Nichols y Henry Lemly, fue adoptar las tácticas propuestas por Upton para el Ejército de los EE. UU. En consonancia, Nichols registró en 1881 sus traducciones de Lecciones para la Artillería y los Estados Mayores y Táctica de la Artillería (Diario Oficial, 1881, junio 16). Pocos meses después, Lemly y el coronel Alejandro B. Ruiz registraron su traducción al castellano de la obra de Upton Táctica de infantería para una y para dos filas adaptada a la topografía americana y a los rifles de última invención (Diario Oficial, 1881, octubre 8).

Como si se tratase de una competencia, en enero de 1882 Francisco J. Vergara también registró sus obras Instrucción y maniobras de las tres armas, desde la escuela del recluta hasta la de división, solas y reunidas y Servicio en campaña (Diario Oficial, 1882, enero 3, p. 9.991). En realidad, durante este periodo no escaseó el registro de manuales y cartillas para uso militar ante las autoridades de gobierno. Previamente, en 1881, Vergara había sometido su libro Teoría del arte militar a evaluación de la Secretaría de Guerra, que a su vez lo reenvío al estadounidense Nichols.

Este rechazó el libro de Vergara sustentado en tres razones: primera, ya existía uno similar del belga Sagher, ya mencionado; segunda, con varios errores propios de alguien que no era militar, el libro solo resumía viejas teorías francesas o alemanas, desconociendo el "sistema de guerra" en Colombia; finalmente, como tercera razón Nichols subrayó que los militares colombianos necesitaban libros prácticos donde se estudiaran las campañas del país, las cumplidas desde Bolívar, pasando por Mosquera y Pedro Herrán, hasta Julián Trujillo (Archivo General de la Nación [AGN], 1881, t. 1230, fl. 172-173).

Regresando a la traducción de las tácticas de Upton, allí se advierte que son aplicables para el uso de fusiles Remington, Peabody-Martini y Sharp. No excluye los fusiles de repetición, sino que para estos debían hacerse pequeńas modificaciones en los movimientos del soldado (Upton, 1883, p. 39). Nada más ajustado a la realidad, pues en 1882 el mismo Lemly fungió de agente para importar 5.000 fusiles Peabody-Martini calibre .43, con bayoneta cuadrangular. También un millón de cápsulas para fusil y 25 máquinas de cargar cápsulas. Luego, con el conflicto de 1885, el gobierno colombiano adquirió 2.000 fusiles Remington, "modelo español" calibre .43 (AGN, 1883 , t. 1233, fl. 452-453).

En consecuencia, el gobierno colombiano determinó que debía adoptarse una táctica militar, bien el "sistema espańol o norteamericano", para uso en el Ejército como en la Escuela Militar; al efecto convocó una comisión de oficiales generales (Diario Oficial, 1882, octubre 19, p. 11.080-81). La comisión incluyó a los generales en jefe Sergio Camargo y Pedro J. Sarmiento; los generales de división Fernando Ponce, Ricardo Acevedo, Manuel D. Montúfar y José M. Vezga, y el general de brigada Pedro Arnedo (Diario Oficial, 1882, noviembre 8, p. 11.156). 
El acta final de la comisión concluyó recomendando la táctica de Upton. Al año siguiente, por Decreto 560 de 1883, el gobierno nacional determinó que debía seguirse esa táctica estadounidense para la instrucción y las maniobras de infantería de la Guardia Colombiana. Al respecto cabe anotar que la profundidad del cambio de táctica, que supuso formaciones más flexibles y de guerrilla, amerita investigarse en su impacto sobre el nivel de mortandad y observancia del derecho de gentes en los conflictos decimonónicos en Colombia.

Las tácticas de Upton rigieron desde entonces hasta entrado el siglo XX. De hecho, en 1901 se advierte castigo para quienes no la aplicaran (Ministerio de Guerra, Boletín, 1901, septiembre 21, p. 357), pese a la presión de otras influencias foráneas. Entre estas se puede mencionar la de una misión militar francesa que, en 1898, no obstante permaneció un año escaso, procuró adaptar un manual de infantería, aunque mantenía algunos movimientos de táctica de Upton por no tenerlos el reglamento francés y ser muy usados en Colombia (Ministerio de Guerra, Boletín, 1899, octubre 21, p. 329). Obviamente, con esta misión Francia también vendió fusiles al gobierno conservador de Colombia luego de que estallara el conflicto de 1899; venta que fue considerada como un respaldo oficial del país europeo (Fischer, 2001, p. 88).

Entre quienes apoyaron la misión francesa estuvo el entonces coronel Vergara. Recuérdese que uno de sus libros fue rechazado por el estadounidense Nichols. Vergara, como director del Boletín Militar, promovió la obra francesa pese a su corta estancia. Un ejemplar de este boletín, en 1903, incluyó el informe del general Antonio Laverde sobre una propuesta para un reglamento de infantería presentado al Ministerio de Guerra y sobre la cual preparó una demostración "práctica de los dos sistemas, el de Upton y el francés” (Ministerio de Guerra, Boletín, 1903, junio 27, p. 721). Laverde fue el encargado de la instrucción militar después del conflicto de 1899, con el apoyo del oficial chileno Luis Alberto Arenas.

En efecto, Laverde escribió el Reglamento para los ejercicios y maniobras de los cuerpos de infantería. El texto fue examinado por una comisión que lo comparó con el de Upton y que llegó a la conclusión de que era mejor el nacional porque

simplificaba el manejo del arma, amplía la instrucción individual, comunica brío y marcialidad al soldado; tiene como base conservar reunidos los soldados con sus jefes natos, para no romper las agrupaciones fundamentales y legales, base única de toda organización y táctica dignas del nombre de tales, y que no respetaba el de Upton, aplicable más bien a una caballería. (Ministerio de Guerra, 1904, Informe, 1904, p. xliii)

\section{Discípulos pragmáticos en la escuela colombiana}

Quedó dicho que el texto de Upton fue publicado en Colombia, en 1881, por Lemly y el coronel Ruiz, ambos profesores de la Escuela Militar. En adelante vale profundizar sobre los estadounidenses llegados a Colombia un ańo antes, contratados por el gobierno colombiano: el teniente activo Henry Rowan Lemly (1851-1925) y el subteniente retirado Thomas B. Nichols (18481902), graduados de la misma clase de 1872 en West Point. Justo antes de ingresar aquellos a la Academia, el Ejército de los EE. UU. había adoptado las tácticas de infantería de Upton. Pero 
siendo alumnos en la Academia, Upton también fue su comandante de cadetes e instructor en tácticas de artillería, infantería y caballería. Es decir, Colombia había contratado a dos discípulos de Upton.

No obstante, el registro militar sobre Nichols es muy reducido: nació en Canadá y se graduó como subteniente cuando contaba 24 años. Acumuló casi cuatro años de experiencia en las fronteras del oeste de los EE. UU. hasta 1876, cuando renunció al Ejército (Cullum, 1879, p. 448). Pero en 1879 figura como oficial activo, al comparecer como testigo ante un comité del Senado estadounidense. Allí declaró que un lustro antes fue parte de un regimiento de caballería, en campaña contra "indios hostiles" en el territorio de Texas (Senate of the United States, 1879, p. 1), parte de la guerra de Red River, para someter a los indios Comanche, Cheyenne y Arapaho. Luego de retirarse, fue superintendente de una compañía privada de carga, antes de ser contratado para la Escuela Militar de Colombia.

En el marco del Decreto 632 de 1880, con el cual se reabrió ese año la Escuela Militar, se estipuló que estos dos profesores extranjeros eran para la enseñanza "especialmente de Estado mayor i Artillería” (AGN, 1880, t. 1228, fl. 109; Diario Oficial, 1880, agosto 5, p. 8.156). A Nichols le correspondía dictar servicio de estado mayor, castrametación y "parte política de la ciencia de la guerra" a los oficiales de grado capitán y subalternos de la guarnición de Bogotá (AGN, 1880, t. 1228 , fl. 141; 1881, t. 1230, fl. 194). Pero al llegar pidió plazo para iniciar clases semanas después, arguyendo que estaba enfermo de una pierna. Lemly, en agosto de 1880, comenzó a dictar en la Escuela tácticas de infantería y caballería, marchas y maniobras militares. Pero la impronta estadounidense no se limitó a la táctica.

Entonces, Nichols inspeccionó la Ferrería de Samacá, arguyendo ser comisionado de los gobiernos de Colombia y de los EE. UU., lo cual fue desmentido por ambas instancias. La inspección consta en dos informes diferentes: en uno de enero de 1881 sostuvo que el montaje de la empresa era satisfactorio; en otro, de finales del mismo año, se contradice y asegura que la obra amenazaba ruina. Tal inspección se le encargó asumiendo que era ingeniero con experiencia en una empresa similar en los EE. UU. (Ferrería de Samacá, 1882, p. 19). Sus informes contradictorios se atribuyen a que aspiraba ser director en Samacá, pero el gobierno de Boyacá lo objetó, y luego Nichols intrigó para ser director en la Ferrería de Subachoque (Ferrería de Samacá, 1882, p. 53).

Para mediados de 1881 el entonces director de la Escuela, coronel Rudecindo López, ya había adoptado el Reglamento interno, de disciplina y gobierno, adaptado sobre el de West Point, tal vez, a instancias de Lemly y Nichols. En la celebración del 20 de Julio del mismo año en la Plaza de Bolívar, el programa incluyó ejercicios donde los cadetes aplicaron también ya la táctica de Upton para manejo de Rémington, maniobras de batallón y de guerrilla (sic) (Diario Oficial, 1881, julio 16, p. 9.351).

Cuando sobrevino la muerte intempestiva del director de la Escuela, el Consejo de profesores propuso en su reemplazo al coronel Dimas Atuesta, que era entonces el inspector ayudante de la institución. Al contrario, ese mismo julio, el gobierno nombró director interino a Lemly, no sin antes ascenderlo a teniente coronel ad-honorem del Ejército colombiano; ambos nombramientos fueron confirmados ante la Legación de los EE. UU. en Bogotá (AGN, 1881, t. 1230, fl. 328 y 331). Entonces, Lemly reorganizó el Batallón de cadetes en tres compañías, con sus respectivos oficiales y ayudantes; designó otro ayudante a cargo del material y parque; suprimió el conserje-bedel y el bibliotecario (AGN, 1881, t. 1230, fl. 258, 331 y 348). 
El director anterior también había aprobado cambiar el color negro del uniforme de parada de los alumnos, pasando a ser del mismo color y forma que los de cuartel — de tela gris con adornos negros- El cambio lo sustentó en una razón presupuestal: cuando los uniformes de parada estuvieran muy usados servirían para cuartel. Estos no solo eran parecidos al uniforme de West Point, Lemly instó en algún momento a la Secretaría de Guerra para acelerar la importación de los uniformes encargados a Nueva York. Entonces se importaron libres de impuestos 200 uniformes de parada con sus kepis, 186 chacós de parada, con pompones, y 14 para cadetes (sic), además de 24 silletas para mobiliario de la Escuela (AGN, 1881, t. 1230, fl. 197-198; Diario Oficial, 1881, octubre 20, p. 9.704).

Por la misma época, Lemly también cumplió una gestión similar para la adquisición de 200 rifles Sharp en Nueva York ${ }^{11}$. Estos modelos 1878 , calibre $4 \mathrm{~V}$, se pidieron con sus bayonetas triangulares, brochas, destornilladores y porta-rifles completos; además de 100.000 cápsulas con bala 4V, otras 10.000 cápsulas sin bala (para el 20 de Julio), 25.000 fulminantes, 10 libras de grasa, 4 juegos de instrumentos para recargar cápsulas y 4 instrumentos para ajustar las cápsulas dilatadas. Como agente importador actuó la firma de Camacho \& Vengoechea (Diario Oficial, 1882, mayo 1, p. 10.416).

No obstante, Lemly parecía fiel a los deberes para los que fue contratado. En mayo de 1882 escribió al secretario de Guerra recordando que su contrato era para impartir conocimientos como "Oficial de Artillería de los Estados Unidos". El asunto es que el Gobierno creía inconveniente sacar cańones del parque nacional para disposición de la Escuela. Por ello, Lemly propuso que martes y jueves de cada semana los cadetes fueran llevados al Cuartel de Artillería para practicar con las piezas necesarias. Un mes después, en calidad de agente de la Providence Goal Company, vendió al gobierno colombiano 5.000 rifles Peabody-Martini y un millón de cápsulas respectivas (AGN, 1882, t. 1232, fl. 398, 452-453). Para esta época Lemly se desempeñaba como subdirector y, en junio, quedó encargado de la Escuela hasta la llegada del nuevo director, el general Sergio Camargo.

\section{El liberal costumbrista Lemly}

Mientras Upton fue considerado un genio, Lemly sería un típico estadounidense pragmático. A diferencia de aquel, provenía de uno de los estados esclavistas, North Caroline, readmitido en 1868 como parte de los EE. UU. y gracias a lo cual este mismo año obtuvo una beca para West Point (Mackintosh, 2007, p. 1). En su país alcanzó tardíamente el grado de mayor; en Colombia recién llegado fue nombrado teniente coronel, director de la Escuela Militar y permaneció más de siete ańos en tres periodos alternos.

Quedó dicho que cursó sus cuatro años de Academia bajo la influencia de Upton. También, como Nichols, graduado de subteniente, Lemly fue asignado a unidades de caballería en la frontera del oeste (Cullum, 1879, p. 439), participando en las expediciones de Big Horn y Yellowstone.

11 Como H. Lemly de Nueva York figura también en 1887 vendiendo al gobierno 400 uniformes para la policía de Bogotá (Diario Oficial, 1887, febrero 5, p. 142). 
Entonces, en 1876, su regimiento, apoyado por guerreros Crow y Shoshone, se enfrentó contra los indios Sioux; precisamente aquí, en la Batalla de Rosebud, parece iniciarse como cronista. Obligado el regimiento a retirarse con muchas bajas, describió a los Sioux así: "No ha existido mejor caballería irregular" (Lemly, 1975, p. 15).

Luego estuvo en Fort Robinson (Nebraska State Historical Society, s. f., p. 18), base para someter a los Cheyenne y en donde su líder, Caballo Loco, fue asesinado después de haberse entregado. Lemly, como testigo de excepción, pues el día del hecho estaba de oficial de servicio, escribió una crónica ${ }^{12}$ que un diario neoyorquino publicó una semana después como anónimo. Pero convivió más tiempo con los indios Arapaho, a quienes llamó sus amigos, derivando en escritor costumbrista ${ }^{13}$ (Lemly, 1880, 1886).

Después de seis años en el oeste fue asignado a un fuerte de artillería costera en Nueva York, entre 1878 y 1880, cuando ascendió a teniente. En junio de este último ańo, el Congreso de los EE. UU. autorizó su viaje como profesor de la Escuela Militar en Colombia, donde permaneció hasta agosto de 1883. De regreso a los EE. UU., luego de otra breve asignación, estuvo en la Escuela de Artillería entre 1884 y 1885. Igual que Upton —recuérdese que fue director allí un lustro antes-, Lemly aprovechó su ambiente para redactar un estudio histórico sobre la artillería del siglo XIX y las plazas fortificadas.

También en 1884 publicó en Nueva York su obra Ejercicios gimnásticos ${ }^{14}$, tratado que si bien dedicó a los cadetes colombianos, evidencia el liberalismo de Lemly al proponer su uso por otros públicos ("latinoamericanos", hombres y mujeres, niños y jóvenes), como exigía espacio amplio, luz abundante y aire puro (Lemly, 1884, p. 7). Los primeros ejercicios los tomó de su traducción de la Táctica de Upton, después vienen otros que podían acompañarse con música o para cuya práctica propuso varios aparatos (Brozaz, 1999).

Igual publicó varias crónicas de costumbres. Una sobre Bogotá, adonde llegar le tomó doce días en un trasatlántico desde Nueva York hasta Barranquilla, no menos de diez días remontando el Magdalena hasta Honda y hasta tres días subiendo a lomo de mula a la ciudad; en suma, casi un mes. Como militar comparó a los indios: los estadounidenses eran primitivos, los de la sabana de Bogotá eran más civilizados; sin omitir su condición humilde, se admiró de la gran capacidad de estos como cargueros y, siendo mayoría en las tropas del ejército colombiano, concluyó que "no hay mejor máquina de soldados en el mundo" (Lemly, 1885, p. 57).

Paradójicamente, Lemly, que participó en las "guerras indias" para reducir a sus compatriotas, tomó partido por los muiscas en contra del dominio español ${ }^{15}$. Aún más, se complació

12 Era frecuente que oficiales estadounidenses escribieran a los periódicos; la crónica de Lemly sobre Caballo Loco apareció en New York Sun en septiembre de 1877 (Mackintosh, 2007, p. 4).

13 Lemly publicó dos artículos sobre los Arapaho, y luego sobre Bogotá, en Harper's New Monthly Magazine; esta era la más célebre revista neoyorquina a finales del siglo XIX, plataforma de la nueva élite cultural estadounidense (Colbert, s. f.). También escribió en Magazine of American History United Service, Outing, Cosmopolitan, The Capital y Evening Post.

14 Los libros militares de Lemly, incluyendo su traducción de Upton, el Manual of Strategy (1889, traducción de H. Fix) y El Heliógrafo (1894), fueron reunidas en Washington (Military Information Division, 1898, pp. 69, 82, 239 y 455); uno sobre Bolívar lo reseńamos más adelante.

15 En una crónica sobre los Muiscas, Lemly dice seguir a un historiador Acosta. Allí anexó una carta de William Prescott donde este declara tener tiempo solo para revisar documentos sobre el reinado de Felipe II de España y rechaza una colección de material sobre los Muiscas que le ofreció Acosta (Lemly, 1891, p. 892). En efecto, antes de morir, en 1859, Prescott rechazó un 
de la compra de 2.380 piezas arqueológicas (entre barro, oro, madera y piedra) por el cónsul estadounidense en Colombia W. Randall; una invaluable colección vendida por el que llamó "entusiasta arqueólogo" colombiano Gonzalo Ramos (Lemly, 1891, p. 881). Parece que Lemly tuvo ocasión, si no de recorrer, por lo menos de estudiar las diferentes regiones arqueológicas de Colombia ${ }^{16}$.

Pasadas otras asignaciones, en 1889 fue encargado de recibir los delegados a la primera Conferencia Internacional de Estados Americanos en Washington, donde sirvió como agregado militar. De regreso en Colombia, entre 1890 y 1893, mientras dirigía la Escuela Militar promovió varias prácticas deportivas. En 1891, en revista ante el ministro de Guerra incluyó, además de los tradicionales manejos de fusil y orden cerrado, competencias de carrera y salto (Ávila, 2012, párr. 7). Al ańo siguiente organizó un partido de fútbol entre dos equipos de la Escuela Militar, en uno de los patios de su sede, con asistencia del presidente Caro, y publicó en un periódico bogotano, El Telegrama, el reglamento del juego (Santos, 2005).

En 1894 fue el comisionado por Colombia a la Feria Mundial de Chicago. Distinción que, con anteriores conferidas por el país, le evitaron sanción por ausentismo de su regimiento y ser llamado el "afortunado Lemly" por un periódico neoyorquino ("Fortunate Lieut. Lemly...", 1893, p. 4). Además, volvió por otro ańo, desde octubre de 1895, como instructor del Ejército colombiano. Otra paradoja consistió en que aunque fuera liberal, aquellas distinciones se las otorgaron gobiernos conservadores colombianos de entonces ${ }^{17}$. Justo en la Feria de Chicago se publicaron Los lunares, valses para piano compuestos por el maestro colombiano Pedro Morales y dedicados a Lemly. Morales, por lo menos, era muy amigo de liberales como el dibujante Peregrino Rivera (Bermúdez, 2009, p. 102), quien ilustró la edición de 1896 de la Táctica de infantería de Upton.

De regreso en los EE. UU., en 1898 fue ascendido a capitán y reasignado a la Escuela de Artillería. Pero estalló la guerra de los EE.UU. contra España, por lo cual fue enviado como ayudante del jefe militar de la expedición contra Puerto Rico. De este desempeńo, curiosamente, envió a una revista estadounidense una copla satírica colombiana desfavorable a la intervención ${ }^{18}$ (Lemly, 1899, p. 163). Con 30 años de servicio, pidió su retiro del Ejército estadounidense el mismo año en que estalló el conflicto de 1899 en Colombia y Lemly volvió al país ${ }^{19}$.

A petición del gobierno realizó una marcha nocturna desde Bogotá hasta Honda con dinero para adquirir armas. Descendió por el río Magdalena hasta Barranquilla, en un vapor blindado improvisadamente, y allí embarcó para Nueva York. Las armas compradas pasaron por el istmo

proyecto sobre los Muiscas que le hiciera Joaquín Acosta, reconocido por sus aportes historiográficos en el siglo XIX (Figueroa, 2007, p. 164).

$16 \mathrm{El}$ profesor John F. Scott, de la Universidad de Florida, menciona que Lemly vendió piezas arqueológicas colombianas al Field Museum of Natural History en Chicago (Scott, J. 2005, julio 14, mensaje personal, jfscott@ufl.edu).

17 Un H. Lemly de Nueva York, en 1895, obtuvo el contrato para una fábrica de papel, con privilegio por treinta años y la concesión de 5.000 hectáreas de baldíos para cultivo de materias primas (Diario Oficial, 1895, noviembre 20, p. 823).

18 La carta, incluyendo la sátira, se publicó en The Century Magazine, donde Lemly había publicado un artículo sobre la leyenda muisca de Eldorado. Esta revista competía con la ya mencionada Harpers, dedicada a la actualidad y con más ilustraciones (Cairns, 2000, párr. 23); inicialmente tuvo un sesgo evangelista radical, luego de la Guerra de Secesión se dedicó a promover la reconciliación y el nacionalismo.

19 También, en 1899, un H. Lemly de Nueva York obtuvo otro contrato para navegación en el Putumayo, con privilegio por cinco años y 20.000 hectáreas de baldíos por cada vapor que trajera (Diario Oficial, 1899, noviembre 16, p. 1.170). 
de Panamá para introducirse por Buenaventura. Desde entonces Lemly fue agente de las fábricas de armas, viviendo sucesivamente en París, Berlín, Caracas, San Petersburgo, Londres, Tokio, Pekín e incluso atravesó Rusia en el tren transiberiano (Thayer, 2014, p. 188). Pasó por Bogotá de nuevo en 1914, antes de ser reactivado en el servicio cuando los EE. UU. entraron a la Primera Guerra Mundial. Asignado entonces al departamento logístico del Ejército, en 1918 fue ascendido a mayor y a los dos ańos pasó al retiro definitivo.

Igual que en Puerto Rico, en 1919 Lemly lamentó la conducta de los EE. UU. a raíz del debate sobre el Tratado Herrán-Hay que la Primera Guerra Mundial había opacado ${ }^{20}$. Aceptaba que el Senado colombiano no firmara, dada la negativa del expresidente Roosevelt a incluir una cláusula de pesar, recordando que en 1870 Colombia ofreció a los EE. UU. la construcción del canal y ante su rechazo acogió la oferta de Francia. Lemly subrayó que los EE. UU. desembarcaron tropas en Panamá varias veces durante el siglo XIX para apoyar al gobierno colombiano, según el tratado de 1846, pero que en 1903 afectó los derechos colombianos sobre el canal, sobre el ferrocarril y sobre su propio territorio (Lemly, 1919b, pp. 571-573).

Poco antes de morir, publicó un extenso libro sobre Bolívar (Lemly, 1923). Este lo dedicó a Colombia en recuerdo de su generosa hospitalidad, acotando que mientras Washington era bien conocido en Suramérica, poco se sabía del Libertador en los EE. UU.

\section{A modo de conclusión}

Este artículo constató la influencia liberal estadounidense sobre el Ejército colombiano entre 1880 y 1904 . Desde cuando llegó la misión estadounidense contratada para enseñar en la Escuela Militar (1880) hasta cuando se adoptó una nueva táctica para las tropas (1904). Al efecto, el artículo revisó cinco aspectos: i) el entorno conflictivo para una reforma militar, ii) el perfil liberal de Upton, iii) la adopción de tácticas en el contexto colombiano, iv) el pragmatismo estadounidense en la escuela colombiana y, finalmente, $v$ ) el perfil liberal costumbrista de Lemly.

Respecto al carácter estadounidense de la reforma militar, puede especularse que Colombia y los EE. UU. no se diferencian mucho en su conflictivo proceso de consolidación como Estadonación. Durante el siglo XIX, los EE. UU. vivieron en conflictos recurrentes después de lograr su independencia, el más largo de ellos el de las "guerras indias"; el más traumático el de la Guerra de Secesión (1861-1865); el más rentable el de la guerra con México (1846) y le sigue el de la guerra con España (1898); el que constituyó una prueba de fuerza fueron las guerras con Gran Bretańa (1812) y las de Berbería; sin contar conflictos menores para conquistar territorio. En ese proceso, los EE. UU. procuraron marginarse de las disputas europeas de poder, de allí que se le califique de aislacionista, incluso sin darle mayor importancia al desarrollo del Ejército.

20 Sobre el asunto, Lemly debatió por carta a través de North American Review, una revista literaria y progresista de Boston. Son tres entregas de la revista en 1919: en julio, un artículo de William R. Thayer donde ataca a Colombia; en octubre, Lemly objetó y el aludido respondió; en diciembre, nueva respuesta de Lemly (1919a, p. 859). 
En ese contexto se moldeó el espíritu liberal de Upton, un militar de carrera que se destacó en la Guerra de Secesión por innovar las tácticas del Ejército con el fin de disminuir las bajas y, sin embargo, doblegar al contrincante. Para esto aprovechó el privilegio de haber comandado las tres armas (artillería, infantería y caballería), así como las fuerzas regulares y de voluntarios. Si bien fue apoyado por el general Sherman, quien lo envió a evaluar las fuerzas europeas y asiáticas, igual que fue asignado a West Point para implantar las nuevas tácticas, Upton fue controvertido sobre su propuesta de reforma del Ejército. Esto por cuanto introducía una política militar ajena a la tradición estadounidense que relegaba al ciudadano armado y disponía de una fuerza armada permanente y profesional.

Las nuevas tácticas de Upton llegaron a Colombia directamente a la Escuela Militar. En esta época, dado que los dirigentes colombianos coincidían con los estadounidenses sobre lo oneroso de un ejército permanente, el bagaje español de la organización militar siguió imperando, aunque circulaban manuales europeos, hasta que los estadounidenses Nichols y Lemly impusieron el modelo de su compatriota. Entre 1883 y 1904, solo atendiendo a la expedición de las normas respectivas, se empleó la táctica de Upton en consonancia con la adquisición de fusiles de ese país. $\mathrm{Al}$ respecto, cabe destacar que la historiografía no ha abordado el impacto del modelo táctico en el desarrollo de los conflictos en Colombia, como tampoco ha evaluado cierta profusión de manuales militares incluso desde 1830 hasta 1904.

Nichols y Lemly fueron dos militares egresados de West Point, quienes se desempeñaron en las unidades de frontera durante las "guerras indias". Cuando llegaron a Colombia en 1880, Nichols era subteniente retirado luego de cuatro años de servicio y Lemly había sido recientemente ascendido a teniente. Desde entonces, la Escuela fue afianzando la influencia estadounidense en reglamentos, uniformes, armamento, régimen interno y, por supuesto, las tácticas militares de Upton. Lemly no solo fue ascendido a teniente coronel ad honorem, sino que fungió como director de la Escuela y como agente de fábricas militares de los EE. UU.

Más pragmático que su preceptor Upton, Lemly vivió de cerca la derrota de las tropas estadounidenses en Little Big Horn y la muerte del líder indígena Caballo Loco. En la guerra entre los EE. UU. y España, así como en la Primera Guerra Mundial, cumplió un papel muy modesto, mientras que en Colombia pudo destacar y permaneció tres periodos separados (1880-1883, 1890-1893, 1895) e hizo algunas otras visitas esporádicas. En una última obra extensa, un libro sobre Bolívar, Upton reconoció la generosidad de Colombia. Mucho antes escribió un par de manuales militares, pero sí fue profuso como cronista de costumbres. En la Escuela Militar, además, impulsó el atletismo, el fútbol y el tenis, por lo cual se le considera uno de los introductores de esos deportes al país. 


\section{Referencias}

1. Agüero, F. (1995). Militares, civiles y democracia: La España postfranquista en perspectiva comparada. Madrid: Alianza.

2. Ambrose, S. (1964). Emory Upton and the Armies of Asia and Europe. Military Affairs, 28 (1), 27-32. Recuperado de http:// links.jstor.org/sici?sici=0026-3931\%28196421\%2928\%3a1\%3c27\%3aeuatao\%3e2.0.co\%3b2-k

3. Arancibia, R. (2002). La influencia del ejército chileno en América Latina 1900 - 1950. Santiago: CESIM.

4. Archivo General de la Nación. (AGN). Sección República, Fondo Secretaría de Guerra y Marina, tomos 1228-1233, varios folios.

5. Ávila, R. (1 de abril de 2012). Henry Rowan Lemly, el pionero. El Espectador. Recuperado de http://www.elespectador.com/deportes/henry-rowan-lemly-el-pionero-articulo-335875

6. Baker, K. (2012). Emory Upton and the Shaping of the U.S. Army. HistoryNet. Recuperado de http://www.historynet.com/emoryuptonandtheshapingoftheusarmy.htm

7. Bermúdez, E. (2009). Cien años de grabaciones comerciales de música colombiana. Los discos de 'Pelón y Marín' (1908) y su contexto. Ensayos. Historia y teoría del arte 17, 87-134. Recuperado de http://www.bdigital.unal.edu. co/43524/1/45872-222516-1-SM.pdf

8. Bogdandy, A., Häußler, S., Hanschmann, F., \& Utz, R. (2005). State-Building, Nation-Building, and Constitutional Politics in Post-Conflict Situations: Conceptual Clarifications and an Appraisal of Different Approaches. Max Planck Yearbook of United Nations Law, 9, 579-613. Recuperado de www.mpil.de/files/pdf2/mpunyb_bogdandyua_9_579_613.pdf

9. Brozaz, M. (1999). La recuperación del trapecio en la educación física: de la historia a la didáctica. Educación Física y Deportes - Revista Digital, 4 (17). Recuperado de http:// www.efdeportes.com/efd17/trapeci.htm

10. Cairns, W. (2000) Later Magazines. In W. Trent, J. Erskine, S. Sherman \& C.Van Doren (Eds.), The Cambridge History of English and American Literature (Vol. 17). New York: G.P. Putnam's. Recuperado de http://www.bartleby. com/227/1210.html 1/2

11. Cardona, J. (3 de noviembre de 2013). El legado de los liberales radicales del siglo XIX. El Espectador. Recuperado de http://www.elespectador.com/noticias/politica/el-legado-de-los-liberales-radicales-del-siglo-xix-articulo- 456407

12. Clark, J. (2009). The Many Faces of Reform: Military Progressivism in the U.S. Army, 1866-1916 (PhD. Diss., Dept. of History). Durham, NC.: Duke University. Recuperado de http://dukespace.lib.duke.edu/dspace/bit-
stream/handle/10161/1310/D_Clark_Jason_a_200908.pdf.sequence $=1$

13. Colbert, A. (s. f.). Harper's New Monthly Magazine. American History through Literature 1870-1920. Recupe-rado de http://www.encyclopedia.com/history/culture-magazines/ harpers-new-monthly-magazine

14. Comisión Histórica del Conflicto y sus Víctimas. (febrero, 2015). Contribución al entendimiento del conflicto armado en Colombia. Bogotá: La Comisión. Recuperado de http://static. elespectador.com/archivos/2015/02/1952328280f79f83ccb8b9929c8d8fa5.pdf

15. Confederación Granadina. (1859). Código militar. Los doce códigos del Estado de Cundinamarca (pp. 315-420). Bogotá: Imprenta Echeverría. Recuperado de: de http://goo.gl/ hPbcXp

16. Cullum, G. (1868). Biographical Register of the Officers and Graduates of the U.S. Military Academy at West Point (Vol. 2). New York: D. Van Nostrand. Recuperado de https:// ia601409.us.archive.org/9/items/biographicalregi02cull/ biographicalregi02cull.pdf

17. Cullum, G. (1879). Biographical Register of the Offcers and Graduates of the U.S. Military Academy, from 1802 to 1867 (Vol. 3). New York: James Miller Publisher. Recuperado de https://ia802700.us.archive.org/29/items/biographicalregi03cull/biographicalregi03cull.pdf

18. Deas, M. (1994). Prólogo. En Pinzón P., El ejército y las elecciones: Ensayo histórico (pp. 9-13). Bogotá: Cerec.

19. Dinnen, S. (2007). The Twin Processes of Nation Building and State Building. SSGM Briefing Note, 1, 1-4. Recuperado de https://www.researchgate.net/publication/283136196_The_ Twin_Processes_of_Nation-Building_and_State-Building

20. Duroselle, J. (1965). Politica exterior de los Estados Unidos: de Wilson a Roosevelt (1913 1945). México: Fondo de Cultura Económica.

21. Esquivel, R. (2010). Neutralidad y orden: politica exterior y militar en Colombia, 1886-1918. Bogotá: Universidad Javeriana.

22. Estados Unidos de Colombia. Diario Oficial. Bogotá: 1880-1886 (varios números).

23. Ferrería de Samacá. (1882). Dos informes contradictorios de Thomas B. Nichols, sobre el estado de esa empresa. Bogotá: Imprenta Zalamea. Recuperado de http://babel.banrepcultural.org/cdm/singleitem/collection/p17054coll10/ $\mathrm{id} / 2310$

24. Figueroa, J. (2007). El Compendio de Joaquin Acosta y la construcción de memoria histórica en Nueva Granada (1830-1848) (Trabajo de grado de Maestría en Historia). Universidad Nacional de Colombia, Bogotá. 
Recuperado de http://www.bdigital.unal.edu.co/10019/1/ Disserta\%C3\%A7\%C3\%A30\%20Juan\%20David\%20 Figueroa.pdf

25. Fischer, T. (2001). De la guerra de los Mil Días a la pérdida de Panamá. En G. Sánchez \& M. Aguilera (Eds.), Memoria de un país en guerra. Los Mil Días: $1899-1902$ (pp. 33-76). Bogotá: Planeta.

26. Fitzpatrick, D. (2001). Emory Upton and the citizen soldier. The Journal of Military History, 65 (2), 355-389. Recuperado de http://search.proquest.com.nduezproxy.idm.oclc.org/military/ docview/195638313/fulltext/504bdd346b984439pq/5?accountid $=12686$

27. Fortunate Lieut. Lemly; Secretary Lamont Exempts Him from His Recent Order. (May 16, 1893). The New York Times, p. 4. Recuperado de http://query.nytimes.com/ mem/archive-free/pdf?res=9806e7db1431e033a25755cla9639c94629ed7cf

28. González, F. (2006). Partidos, guerras e Iglesia en la construcción del Estado-nación en Colombia (1830-1900). Medellín: La Carreta.

29. History.com. (2010). American-Indian Wars. Recuperado de http://www.history.com/topics/native-american-history/american-indian-wars

30. Kirshner, R. (1999). The Class of 1861: Custer, Ames, and their classmates after West Point. Carbondale, IL: Southern Illinois University Press. Recuperado de edelweissco.by/free books $/$ download/asin=0809320665\&type=full

31. Lemly, H. (1880). Among the Arrapahoes. Harper's New Monthly Magazine, 60 (358), 493-501. Recuperado de http://www.unz.org/Pub/Harpers-1880mar-00494

32. Lemly, H. (1884). Ejercicios gimnásticos. Nueva York: Appleton. Recuperado de https://archive.org/stream/ejerciciosgimnas00leml? ref=ol\#page/n3/mode/2up

33. Lemly, H. (1885). Santa Fe de Bogotá. Harper's New Monthly Magazine, 71 (412), 47-58. Recuperado de http:// www.unz.org/Pub/Harpers-1885jun-00047

34. Lemly, H. (1886). The Story of Feather Head. Harper's New Monthly Magazine, 72 (432), 899-903. Recuperado de http://www.unz.org/Pub/Harpers-1886may-00899

35. Lemly, H. (1891). Who was El Dorado? The Century Magazine, 42 (6), 881-891. Recuperado de http://www. unz.org/Pub/Century-1891oct-00881

36. Lemly, H. (1899). A Quotation Concerning the "Maine". The Century Magazine, 58 (1), 163. Recuperado de http:// www.unz.org/Pub/Century-1899may-00163a03

37. Lemly, H. (Dec., 1919a). Colombia, Major Lemly, and Mr. Thayer. The North American Review, 210 (769), 859-860. Recuperado de http://www.jstor.org/stable/25120419

38. Lemly, H. (Oct., 1919b). Colombia and 'Blackmail'. The North American Review, 210 (767), 571-573. Recuperado de http:// www.jstor.org/stable/25120367
39. Lemly, H. (1923). Bolivar: Liberator of Venezuela, Colombia, Ecuador, Peru and Bolivia. Boston: The Stratford Co. Recuperado de http://ia601002.us.archive.org/15/items/bolivarliberat00le$\mathrm{ml} /$ bolivarliberat00leml.pdf

40. Lemly, H. (1975). Fighting the Indians. En J. Carroll (Ed.), The Papers of the Order of Indian Wars (pp. 13-18). Fort Collins, Co.: The Old Army Press. Recuperado de http://www.astonisher.com/archives/museum/rosebud/ henry_lemly_rosebud.html

41. Mackintosh, J. (2007). Fighting Crazy Horse in the great Sioux War. The story of Lieutenant Henry Rowan Lemly of Forsyth County. Recall, 23 (2), 1-4. Recuperado de http:// ns50.webmasters.com/*ncmhs.net/httpdocs/RecallF07.pdf

42. Mahan, A. (2000). El interés de Estados Unidos de América en el poderío maritimo. Bogotá: Universidad Nacional.

43. Mann, M. (1991). El poder autónomo del Estado: sus orígenes, mecanismos y resultados. Revista Académica de Relaciones Internacionales, 5 (2006, noviembre), 1-43. http://www.relacionesinternacionales.info/ojs/article/download/49/42.pdf

44. Martínez, A. (2012). Historia de la Guardia Colombiana. Bucaramanga: Universidad Industrial de Santander.

45. Military Information Division. (1898). Sources of Information on Military Professional Subjects. Washington: Government Printing.

46. Millis, W. (1956). Arms and Men. A Study of American Military History. New York: Mentor Book.

47. Ministerio de Guerra. Boletín Militar. Bogotá: 1899- 1903.

48. Ministerio de Guerra. (1904). Informe del Ministro de Guerra al Congreso. Bogotá: Imprenta de Vapor.

49. Ministerio de Relaciones Exteriores. (1957). Anales Diplomáticos y Consulares de Colombia (tomo 7). Bogotá: Empresa Nacional de Publicaciones.

50. Mújica, E. (2014). Bajo el signo de la desmovilización. La política militar estadounidense durante la reconstrucción, 1863-1877. Signos Históricos, 32, 156-182. Recuperado de http://www.scielo.org.mx/pdf/sh/v16n32/v16n32a6.pdf

51. Nebraska State Historical Society. (s. f.). Historical Note. Fort Robinson (Neb.). Reference Collection, RG1517. AM. Recuperado de http://nebraskahistory.org/lib-arch/ research/manuscripts/organize/fortrob.pdf

52. Nobel Foundation. (2014). Elihu Root Biographical. Nobelprize.org. Recuperado de http://www.nobelprize. org/nobel_prizes/peace/laureates/1912/root-bio.html

53. Ocampo, J. (1984). Colombia y la economía mundial 18301930. Bogotá: Siglo XXI.

54. Ortiz, L. (2004). Fusiles y plegarias. Guerra de guerrillas en Cundinamarca, Boyacá y Santander, 1876-1877. Medellín: Universidad Nacional de Colombia.

55. Ortiz, L. (2014). La guerra civil de 1876-1877. En J. Rueda (Comp.), Guerra y rebelión en la década de 1870: 
Estados Unidos de Colombia (pp. 23-112). Bucaramanga: Universidad Industrial de Santander.

56. Palacios, M. (1999). Parábola del liberalismo. Bogotá: Norma.

57. Pérez, H. (2007). El nacionalismo católico colombiano: un 'estilo de pensamiento', 1870-1946. En J. González (Ed.), Nación y nacionalismo en América Latina (pp. 125-152). Bogotá: Universidad Nacional de Colombia. Recuperado de http://www.bdigital.unal.edu.co/1508/7/06capi05.pdf

58. Puell, F. (2000). Historia del ejército de España. Madrid: Alianza.

59. República de Colombia. Diario Oficial. Bogotá: 18861899 (varios números).

60. Sagher, L. (1878). Nociones de táctica de infanteria, de caballería i de artillería (Trad. C. Obeso). Bogotá: Imprenta H. Andrade. Recuperado de http://www.banrepcultural.org/ sites/default/files/brblaa758039.pdf

61. Santos, E. (2005, mayo). Fútbol, una pasión incontenible. Credencial Historia, 185. Recuperado de http://www.banrepcultural.org/blaavirtual/revistas/credencial/mayo2005/futbol.htm

62. Senate of the United States. (January 28, 1879). Committee on Military Affairs. Report No. 644. Recuperado de https:// shareok.org/bitstream/handle/11244/40720/Senate-45-3Report-644-Serial-1837.pdf?sequence=1\&isAllowed=y

63. Shrader, Ch. (2000). Schools, Postgraduate Service. En John W. Chambers \& Fred Anderson (Eds.), Oxford Companion to American Military History. New York: Oxford University Press. Recuperado de http://www. encyclopedia.com/history/encyclopedias-almanacs-transcripts-and-maps/schools-postgraduate-service

64. Stewart, R. (2001). Winning the West the Army in the Indian Wars, 1865-1890. En R. Stewart (Ed.), American Military History (Chap. 14). Washington, D.C.: United States Army. Recuperado de http://www.history.army.mil/ books/AMH-V1/PDF/Chapter14.pdf.

65. Thayer, B. (2014). Class of 1872: Henry Rowan Lemly. Cullum's Register 2421. Recuperado de http://penelope. uchicago.edu/Thayer/E/Gazetteer/Places/America/United_ States/Army/USMA/Cullums_Register/2421*.html

66. Thibaud, C. (2003). Repúblicas en armas: Los ejércitos bolivarianos en la guerra de independencia en Colombia y Venezuela. Bogotá: Planeta.

67. Upton, E. (1883). Táctica de infantería para una y para dos filas, adaptada a la topografía americana y a los rifles de última invención. Traducida y arreglada a las necesidades del Ejército de Colombia por Henrique Lemly y Alejandro Ruiz. Bogotá: Imprenta La Luz.

68. Valencia, H. (1987). Cartas de batalla: Una critica del constitucionalismo colombiano. Bogotá: IEPRI.

69. Varas, A. (1988). La autonomía militar en América Latina. Caracas: Nueva Sociedad.

70. Washington Blog. (February 23, 2015). America has Been at War $93 \%$ of the Time - 222 Out of 239 Years - Since 1776. Recuperado de http://www.informationclearinghouse.info/article41086.htm 